\title{
THE EUROPEAN CAMPAIGN: ITS ORIGINS AND CONDUCT
}

\author{
Samuel J. Newland \\ Clayton K. S. Chun
}

June 2011

The views expressed in this report are those of the authors and do not necessarily reflect the official policy or position of the Department of the Army, the Department of Defense, or the U.S. Government. Authors of Strategic Studies Institute (SSI) publications enjoy full academic freedom, provided they do not disclose classified information, jeopardize operations security, or misrepresent official U.S. policy. Such academic freedom empowers them to offer new and sometimes controversial perspectives in the interest of furthering debate on key issues. This report is cleared for public release; distribution is unlimited.

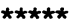

This publication is subject to Title 17, United States Code, Sections 101 and 105. It is in the public domain and may not be copyrighted. 